\title{
Safety evaluation for dams against different modes of surface faults induced by earthquakes
}

\author{
Y. Ariga \\ Graduate School of Science and Technology, Hirosaki University, Japan
}

\begin{abstract}
Safety evaluation against surface earthquake faults is an important subject for long and large structures such as railways, highways, tunnels, banks, dams, and so forth. Normal faults, reverse faults, strike-slip faults and rotational faults, for instance, can be supposed in regard to the modes of surface faults. However, an analytical method for evaluating the safety against surface earthquake faults has not yet been established. So, I devised an evaluation method for safety against various modes of surface earthquake fault by applying a 3-D dynamic analysis method. Applicability of the method proposed was examined by the case study in regard to a concrete gravity dam. As a result, the discontinuous behavior of damfault-foundation system can be simulated by the method proposed. Vertical behavior of a dam by the normal fault or a reverse fault can be analyzed by inputting an acceleration wave in the vertical direction from the half of the rigid base of the 3-D FEM model. Horizontal behavior of the dam by a strike-slip fault can be analyzed by inputting an acceleration wave in the horizontal direction. Discontinuous behavior of the dam against various modes of surface faults can be simulated by combining a horizontal input and a vertical input of acceleration wave.
\end{abstract}

Keywords: safety evaluation, surface fault, 3-D dynamic analysis, concrete dam.

\section{Introduction}

The Upper Crystal Dam, the Upper Howell Dam, and the Old San Andreas were damaged by the surface displacement of the San Andreas Fault during the San Francisco Earthquake in 1906 [1, 2]. The Shih-Kang Dam was destroyed by the vertical relative displacement of about $7.6 \mathrm{~m}$ during the Taiwan Chi-chi Earthquake in 1999 [3]. These historical cases show clearly that the safety 
evaluation against surface displacement induced by an earthquake fault is an important subject for such long and large structures. However, the analytical method for evaluating safety against surface fault displacement has not been practically developed. So, I studied and devised an evaluation method by applying 3-D dynamic analysis in order to simulate the discontinuous behavior of the dam against various modes of surface earthquake faults.

\section{Safety evaluation method}

\subsection{Necessity for safety evaluation against surface fault}

Normal faults, reverse faults, strike-slip faults, and rotational faults can be supposed in regard to the modes of surface faults, as shown in fig. 1. After the Chi-chi Earthquake, some studies on the analytical method in regard to the surface earthquake fault were reported. The analytical methods, such as the applied element method [4], the non-linear stochastic finite element method [5], the Lagrangian particle finite difference method [6], and so forth were reported for evaluating the deformation of ground and the behaviour of structures. But, the analytical method for evaluating the discontinuous behaviour of long and large structure induced by a surface earthquake fault has not been established yet. By such a necessity, I studied the analytical method in order to evaluate the seismic safety of long and large structures against surface earthquake faults.

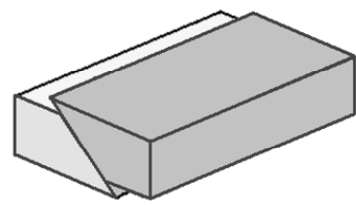

(1) Reverse Fault

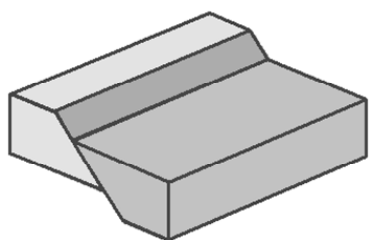

(2) Normal Fault

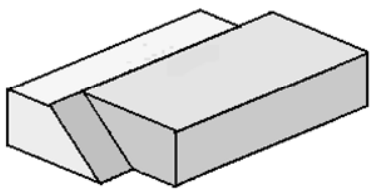

(3) Strike-slip Fault

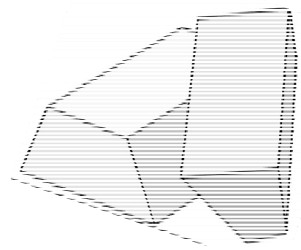

(4) Rotational Fault

Figure 1: Modes of surface fault.

\subsection{FEM model for safety evaluation}

A safety evaluation method was devised by applying 3-D dynamic analysis for a coupled dam-joint-foundation-reservoir system [7]. The boundary condition of the FEM model and the way for inputting earthquake action were especially 
contrived in this study. 3-D dynamic analysis model for a coupled damfoundation-fault system is shown in fig. 2 (the wide range model), which was made by assuming that the surface earthquake fault is distributed just below the dam. The width and the depth of the wide range model are $1335 \mathrm{~m}$ and $1094 \mathrm{~m}$, respectively. Fig. 3 shows the narrow range model around the dam, whose width and the depth of the narrow range model are $445 \mathrm{~m}$ and $218.88 \mathrm{~m}$. The analytical results are indicated by using the narrow analytical model around the dam body.

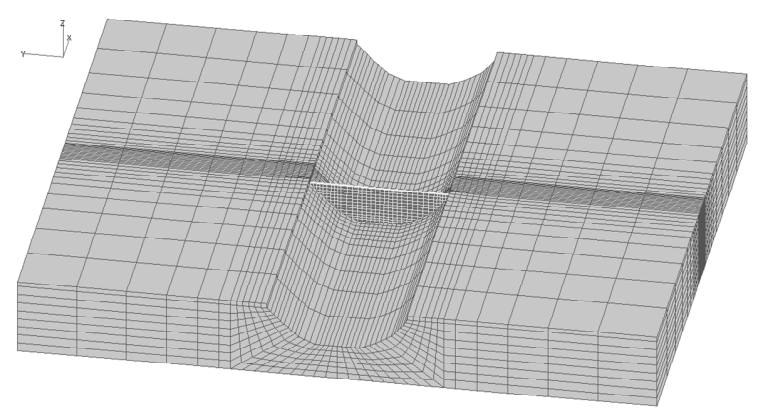

Width:1335.0m, Depth:1094.4m, Height:162.0m

Figure 2: Wide range model.

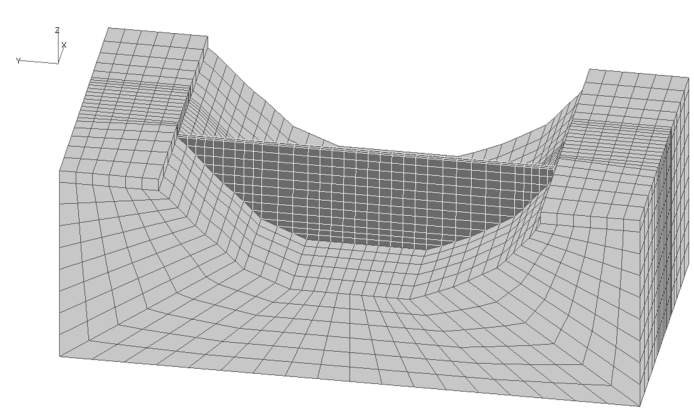

Width:445.0m, Depth:218.88m, Height:162.0m

Figure 3: $\quad$ Narrow range model.

Table 1: $\quad$ Dynamic property values of dam and foundation.

\begin{tabular}{|c|c|c|c|c|}
\hline Items & $\begin{array}{c}\text { Dynamic shear } \\
\text { modulus }\end{array}$ & Density & $\begin{array}{c}\text { Poisson's } \\
\text { ratio }\end{array}$ & $\begin{array}{c}\text { Damping } \\
\text { factor }\end{array}$ \\
\hline $\begin{array}{c}\text { Rock } \\
\text { foundation }\end{array}$ & $9380 \mathrm{~N} / \mathrm{mm}^{2}$ & $2.6 \mathrm{t} / \mathrm{m}^{3}$ & 0.3 & $5 \%$ \\
\hline $\begin{array}{c}\text { Dam } \\
\text { concrete }\end{array}$ & $11032 \mathrm{~N} / \mathrm{mm}^{2}$ & $2.4 \mathrm{t} / \mathrm{m}^{3}$ & 0.2 & $5 \%$ \\
\hline
\end{tabular}


The dynamic property values of the dam and foundation are shown in Table 1 . These property values were identified by the $3-\mathrm{D}$ dynamic simulation analysis for the actual earthquake behaviour of the existing concrete dam based on the earthquake motions recorded during the 1993 Kushiro-oki Earthquake [8].

\subsection{Joint element for modeling of fault and joints}

Fig. 4 shows the distribution of the fault just below the dam, the contraction joints within the dam body, and the peripheral joint along the dam base. These fault and joints are modeled by using 3-D joint elements. The structural and mechanical characteristics of the 3-D joint element are shown in fig. 5 and fig. 6 . In fig. 4, the contact plane of the joint element-1 is composed of foundation rock. The contact plane of the joint element- 2 and element- 3 is composed of dam concrete. The contact plane of the joint element-4 is composed of foundation rock and dam concrete. The dynamic property values of these 4 kinds of joint elements can be set according to the structural material and the condition of contact plane.

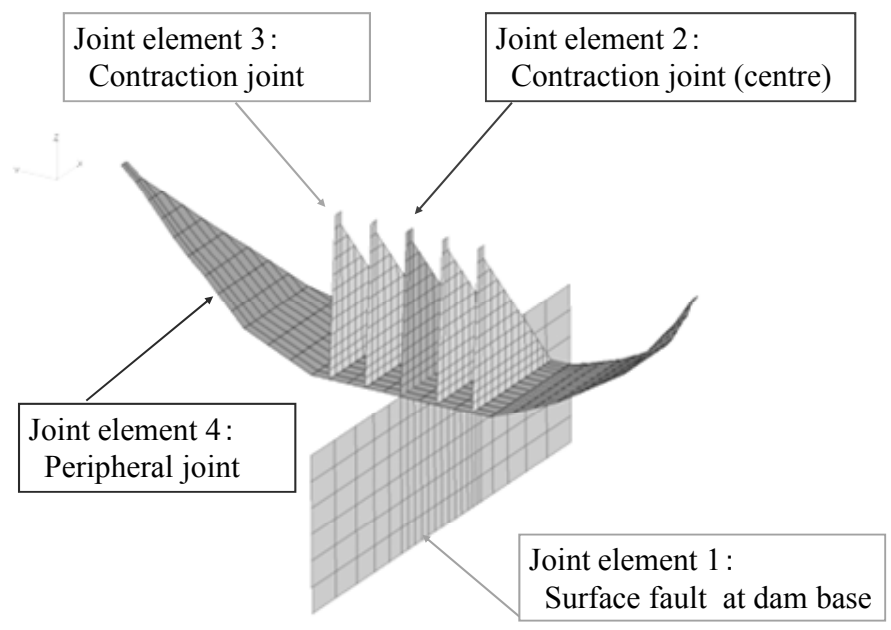

Figure 4: Distribution of fault, contraction joints, and peripheral joint.

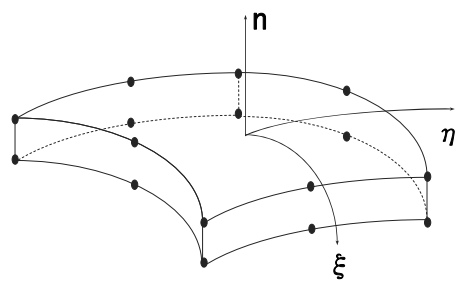

Figure 5: $\quad$ Structure of joint element. 


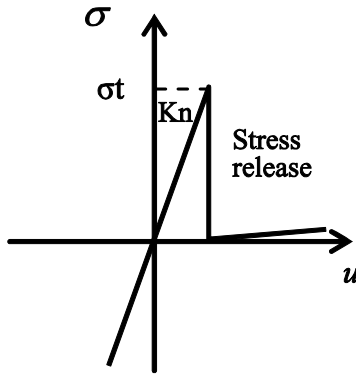

(1) Opening

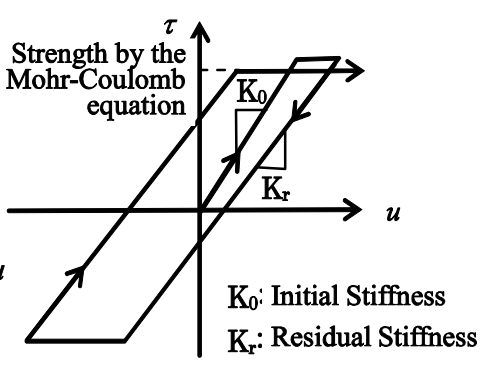

(2) Sliding

Figure 6: Mechanical characteristics of joint element.

The dynamic property values of the fault, the contraction joints, and the peripheral joint are assumed as shown in table 2. Kn is the dynamic shear modulus of joint plane in the normal direction. Ko is the dynamic shear modulus of joint plane in the tangential direction. $\mathrm{C}$ is the shear strength of joint plane. $\varphi$ is the friction angle of joint. $\mathrm{Kr}$ is the dynamic shear modulus after opening or sliding. $\mathrm{C}^{\prime}$ is the residual shear strength of joint plane after opening or sliding. $\varphi^{\prime}$ is the residual friction angle of joint plane after opening or sliding. $\mathrm{H}_{\mathrm{j}}$ is the damping factor of joint. And, $\sigma_{\mathrm{t}}$ is the initial tensile strength of joint. As for $\mathrm{Kn}$ and Ko, the values 10 times as much as the ordinal values are assumed in order to suppress the deformation at the contact plane of joint elements.

Table 2: Dynamic property values of fault and joints.

\begin{tabular}{|c|c|c|c|c|c|c|}
\hline Fault \& Joints & $\begin{array}{c}\mathrm{Kn} \\
\mathrm{N} / \mathrm{mm}^{2}\end{array}$ & $\begin{array}{c}\mathrm{K}_{0} \\
\mathrm{~N} / \mathrm{mm}^{2}\end{array}$ & $\begin{array}{c}\mathrm{C} \\
\mathrm{N} / \mathrm{mm}^{2}\end{array}$ & $\begin{array}{c}\varphi \\
\circ\end{array}$ & $\begin{array}{c}\sigma \mathrm{t} \\
\mathrm{N} / \mathrm{mm}^{2}\end{array}$ & $\begin{array}{c}\mathrm{Hj} \\
\%\end{array}$ \\
\hline $\begin{array}{c}\text { Surface } \\
\text { Fault }\end{array}$ & 243000 & 93000 & 0 & 45 & 0.01 & 5 \\
\hline $\begin{array}{c}\text { Contraction } \\
\text { Joint(centre) }\end{array}$ & 264000 & 110000 & 0 & 45 & 0.01 & 5 \\
\hline $\begin{array}{c}\text { Contraction } \\
\text { Joint }\end{array}$ & 264000 & 110000 & 0 & 45 & 0.01 & 5 \\
\hline $\begin{array}{c}\text { Peripheral } \\
\text { joint }\end{array}$ & 243000 & 93000 & 4.5 & 45 & 3.00 & 5 \\
\hline $\mathrm{Kr}=1 \mathrm{~N} / \mathrm{mm}^{2}$ & $\mathrm{C}^{\prime}=0 \mathrm{~N} / \mathrm{mm}^{2}$ & $\varphi^{`}=45^{\circ}$ & & & \\
\hline
\end{tabular}

\subsection{Boundary condition}

The boundary condition of the 3-D analytical model is shown in fig. 7. Free boundary is set at the right half of bottom boundary in order to generate a discontinuous displacement along the fault. Acceleration wave is input from the left half of bottom boundary, which is set to be rigid base. The right and left lateral boundaries are set to be a roller support in the vertical plane. The front 
and rear lateral boundaries are set as a free boundary. By setting such boundary conditions, the right half of the 3-D analytical model moves by inertia force, and the discontinuous displacements occur along the fault. Consequently, the behavior of dam against the surface fault displacement, the opening and sliding of the contraction joints and the peripheral joint, and the discontinuous relative displacement can be simulated.

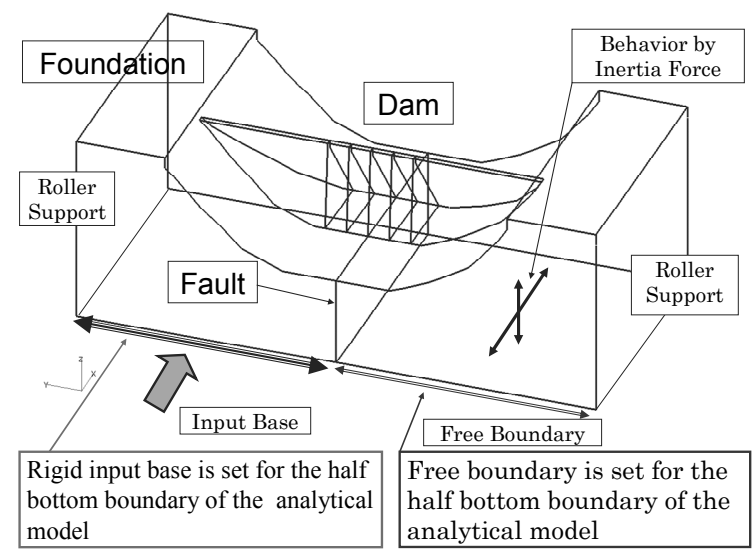

Figure 7: Boundary condition of 3-D FEM model.

\subsection{Acceleration input}

The acceleration wave form shown in fig. 8 is input as a seismic action by the surface fault from the bottom of 3-D FEM model, because it is necessary to input very strong acceleration toward one direction in order to simulate the large discontinuous displacement along the fault, and incidentally to simulate the discontinuous behaviours at the contraction joints and the peripheral joint. The acceleration wave form can be expressed by the curve of second degree, which is convex down ward. The maximum amplitude of acceleration wave is assumed to be $1 \mathrm{G}$, and the duration time is 3 seconds.

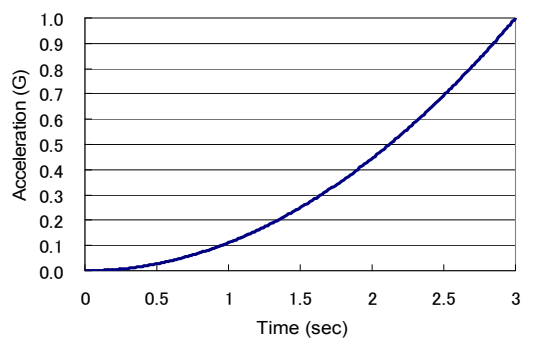

Figure 8: Acceleration input at the bottom boundary. 


\section{Results of analyses}

\subsection{Analytical result in regard to strike-slip fault}

The analytical result in regard to the discontinuous behaviour of the dam when the acceleration wave was input in the horizontal up-down stream direction by using the wide analytical model is shown in fig. 9. The mode of strike-slip fault can be simulated by inputting the acceleration wave in the horizontal direction. In this case, the maximum residual displacement of joints at the centre of dam base was approximately $0.18 \mathrm{~m}$.

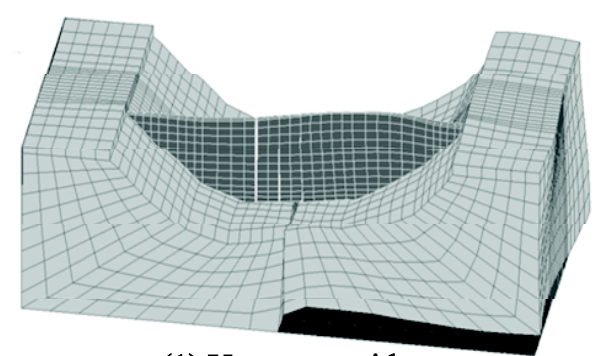

(1) Up-stream side

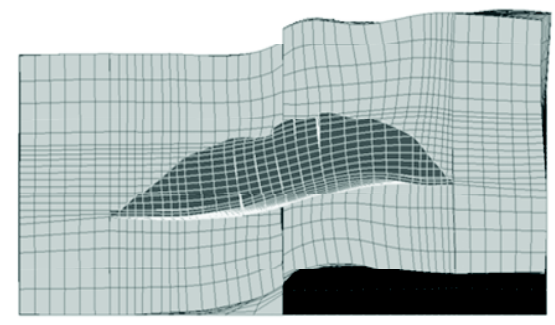

(2) From the above

Figure 9: Analytical result in regard to discontinuous behaviour of dam caused by strike-slip fault.

\subsection{Analytical result in regard to reverse fault}

The analytical result in regard to the discontinuous behaviour of the dam when the acceleration wave was input in the vertical direction by using the wide analytical model is shown in fig. 10. Discontinuous behaviour of the dam caused by reverse fault, or the mode of reverse fault can be simulated by inputting the acceleration wave in the vertical direction. In this case, the maximum residual displacement of joints at the centre of dam base was approximately $2.4 \mathrm{~m}$.

\subsection{Analytical result in regard to rotational fault}

The result when the acceleration wave was input in the vertical direction by using the narrow analytical model is shown in fig. 11. The mode of rotational 
fault can be simulated by inputting the acceleration wave in the horizontal direction and using the narrow model. In this case, the maximum residual displacement of joints at the centre of dam base was approximately $1.9 \mathrm{~m}$.

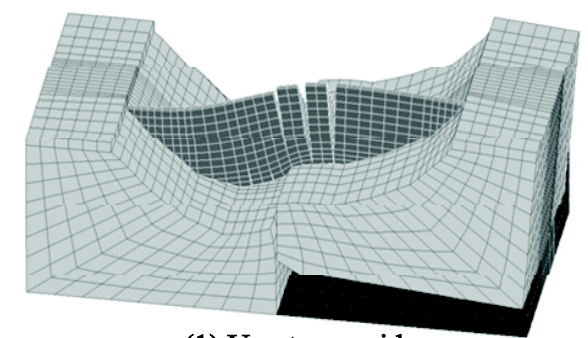

(1) Up-stream side

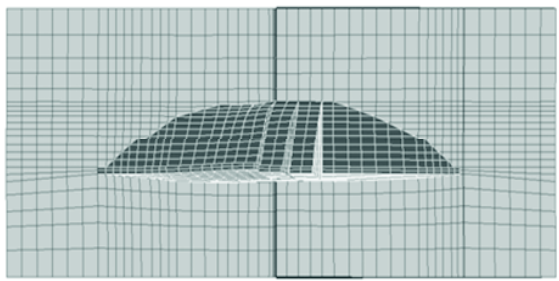

(2) From the above

Figure 10: Analytical result in regard to discontinuous behaviour of dam caused by reverse fault.

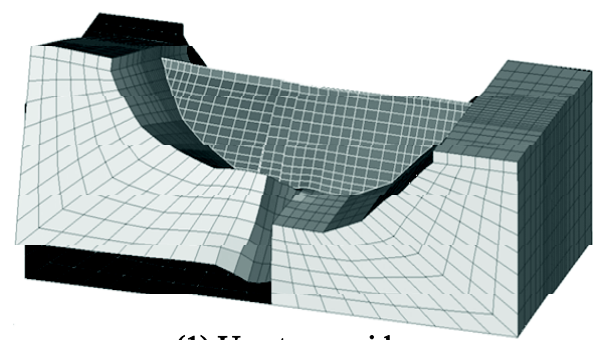

(1) Up-stream side

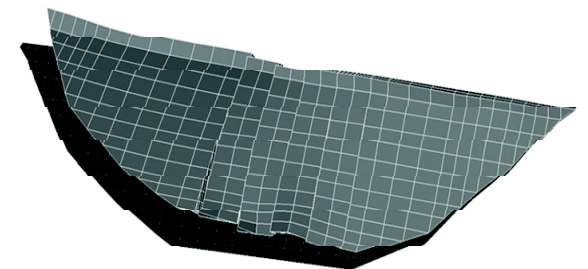

(2) Dam Body (Up-stream side)

Figure 11: Analytical result in regard to discontinuous behaviour of dam caused by rotational fault. 


\section{Conclusions}

Safety evaluation against a surface earthquake fault is an important subject for long and large structures. Therefore, I devised a safety evaluation method against surface fault displacement induced by an earthquake.

The method proposed was developed by applying 3-D dynamic analysis for a coupled dam-joint-foundation-reservoir system.

Applicability of the method proposed was examined by the case study under the assumption that the fault is distributed just below the concrete gravity dam, by taking the actual case of the Shih-Kang Dam.

The discontinuous behavior and the residual displacement of dam-faultfoundation system against various modes of faults can be simulated by the method proposed.

A vertical fault displacement in connection with a reverse fault can be analyzed by inputting an acceleration wave in the vertical direction from the half of the rigid base of 3-D model.

A horizontal fault displacement in connection with a strike-slip fault can be analyzed by inputting an acceleration wave in the horizontal up-down stream direction.

A rotational fault displacement can be simulated by combining a horizontal input and a vertical input.

The residual displacements along the fault and joints will be changed according to the conditions of the input wave and the boundary condition of analytical model. Quantitative evaluation for dynamic property values of contact plane of fault and joints, the frequency and amplitude of input wave, and the verification of validity of the method proposed are the subjects for future study.

The method proposed is effective for evaluating discontinuous behaviors of the coupled dam and surface earthquake fault system. The proposed method can be broadly applied for various kinds of structure-foundation-fault system.

The prediction of earthquake occurrence and the estimation of earthquake motion have been a main theme in the conventional studies on active faults, up to now. If it will be possible to predict the movement of a surface earthquake fault and to forecast a displacement along the surface earthquake fault, more rational safety evaluation will be realized.

\section{References}

[1] Sherard, J. L., Cluff, L. S. and Allen, C. R., Potentially active faults in dam foundations, Geotechnique 24, No.3, 367-428, 1974

[2] Leps, T.M., The influence of possible fault offsets on dam design, Water Power \& Dam Construction, 36-43, 1989

[3] Lee, J. C., Chu, H.T., Angelier, J., Chan, Y. C., Hu, J. C., Lu, C. Y. and Rau, R. J., Geometry and structure of northern surface ruptures of the 1999 Mw=7.6 Chi-Chi Taiwan Earthquake: influence from inherited fold belt structures, Journal of Structural Geology 24, 173-192, 2002 
[4] Meguro, K. and Ramancharla, P. K., Numerical study on the Characteristics of the ground responses in the Near-Fault regions, Proceedings of 11th Japan Earthquake Engineering Symposium, Japanese Geotechnical Society, 397-400, 2002

[5] Hori, M., Anders, M and Gotoh, H., Model experiment and numerical simulation of surface earthquake fault induced by lateral strike slip, Structural Eng./Earthquake Eng., JSCE, Vol.19, No.2, 227-236, 2002

[6] Konagai, K. and Johansson, J., Two dimensional Lagrangian Particle Finite Difference Method for modeling large soil deformation, Structural Eng./Earthquake Eng., JSCE, Vol.18, No.2, 105-110, 2001

[7] Ariga, Y., Cao, Z., Watanabe, H., Seismic stability assessment of an existing arch dam considering the effects of joints, Proceedings of the 21st International Congress on Large Dams, Q.83-R.33, 553-576, 2003

[8] Ariga, Y., 3-D reproduction analyses for actual earthquake behaviours and quantitative evaluation of dynamic property values of existing concrete dams, The Ninth Canadian Conference on Earthquake Engineering, No.1043, p.238-247, 2007 